\title{
Cinema e pulsão: sobre "Irreversível”, \\ O TRAUMA E A IMAGEM
}

Tania Rivera ${ }^{\star}$

\begin{abstract}
Resumo
Partindo de um diálogo entre psicanálise e cinema, buscamos refletir sobre o estatuto da imagem na contemporaneidade. Para além de uma configuração imaginária apaziguadora, é indicada a potencialidade traumática da imagem, por meio da concepção freudiana da lembrança encobridora. Tal dimensão traumática é explorada na análise do filme Irreversível, produção francesa de 2002. A violência não é, nessa obra, apenas mostrada em imagens, mas é posta em cena "entre" as imagens. Em seu agenciamento pulsa uma ameaçadora possibilidade de que aquilo de que se trata na imagem, e que diz respeito à ligação entre sexo e violência não possa ser contado, mas apenas repetido.
\end{abstract}

Palavras-chave: Psicanálise. Cinema. Trauma.

\section{DRIVE AND CINEMA: ABOUT 'IRRÉVERSIBLE", TRAUMA AND IMAGE}

\begin{abstract}
Entwining psychoanalysis and cinema, this paper seeks to reflect about the status of image in contemporary society. This search goes beyond a conformist imaginary configuration to point out the existence of a traumatic potentiality of the image, as indicated by Freudian concept of screen memories. This idea is explored by a discussion about French Director Gaspar Noé production "Irréversible", 2002. In this work, violence isn't simply showed in images but works "between" the images. In its editing pulsates the scaring possibility that something essential about image, related to death and sexuality, can't be told as a history, but destroys everything in a circular repetition.
\end{abstract}

Keywords: Psychoanalysis. Trauma. Cinema.

* Psicanalista e professora da Universidade de Brasília. É doutora em psicologia pela Universidade Católica de Louvain, Bélgica e pesquisadora bolsista do CNPq. Autora de Arte e Psicanálise (2002) e Guimarães Rosa e a Psicanálise. Ensaios entre Imagem e Escrita (2005), ambos por Jorge Zahar Editor. Endereço: SHIS, QI 23, chácara 16, Brasília - DF.

E-mail: taniarivera@uol.com.br 
Cinema e psicanálise são rigorosamente contemporâneos. Enquanto Freud publica com Breuer os Estudos sobre a Histeria, em 1895, os irmãos Lumière fazem as primeiras apresentações públicas de seu cinematógrafo. Freud jamais se ocupou dessa nova arte, apesar de conceder lugar privilegiado em sua obra, como sabemos, a analogias entre aparelhos óticos e o aparelho psíquico. Lou Andreas Salomé notava em texto de 1913, porém, que "a técnica cinematográfica é a única que permite uma rapidez de sucessão das imagens que corresponde mais ou menos às nossas faculdades de representação" e que "o futuro do filme poderá contribuir muito para a nossa constituição psíquica" (SALOMÉ, 1913 apud BAUDRY, 1975, p. 57). A psicanálise talvez tenha dificuldade em se ocupar do cinema por estar dele mais próxima do que se pensa: ambos parecem partilhar uma radical crítica à mímesis - oriunda da criação da fotografia algumas décadas antes - à qual corresponde uma aguda problematização do sujeito. Sem dúvida, como vaticinou Lou Andreas Salomé, o cinema, ao lado da psicanálise, contribuiu para a construção do olhar e do sujeito, ao longo de todo o século XX e do século que se inicia.

$\mathrm{O}$ texto freudiano que mais pode dialogar com o cinema a respeito do estatuto da imagem, "Lembranças Encobridoras", data ainda do período de gênese da sétima arte, tendo sido publicado em 1899. A lembrança encobridora é uma fantasia, mas possui um caráter ultranítido que lhe concede um valor de recordação. Ela é revolucionária por acentuar a distância entre vivência e representação e fazer da imagem uma construção que encobre a verdade, mas de alguma maneira a deixa entrever, podendo portanto ser perscrutada em uma tentativa de reconstruíla - é uma espécie de fotografia deslocada do infantil. Uma fotografia que evoca sequiências fantasmáticas indica algo que não está lá, e que é apresentado de forma encoberta e deve por meio dela ser buscado. Talvez essa seja uma característica da imagem na contemporaneidade: apresentar-se como uma representação que não basta em si mesma, não se esgota como reflexo da realidade, mas põe esta em questão e convida a uma procura por meio da imagem. Uma busca capaz de levar o sujeito a se (re)posicionar ante a imagem, incitando a (re)montagens pulsionais.

O inconsciente, como bem sabemos, não é redutível a imagens, não consiste em um tesouro de imagens, mas em uma série de marcas, impressões que fixam determinados significantes. A análise do sonho, fundadora da psicanálise, bem mostra isso: o quanto a imagem onírica é construída pela linguagem, é pictograma. Mas não se trata tanto de imagem, no sonho, quanto de "texto" do sonho, texto manifesto duplicado pelo texto latente que a análise pressupõe e deve refazer. A imagem em psicanálise é, sobretudo, a lembrança encobridora: cena de grande acuidade visual, por vezes de forma demasiadamente visual e que encobre outra coisa. Cena que remete, portanto, a outra cena, "A Outra Cena" que na pluma de Freud é o inconsciente, cena fundante, mas irrecuperável como lembrança, e que, portanto, deve ser (re)construída. Assim como o nascimento da irmã de Freud, de que ele não se lembra em absoluto, mas guarda a lembrança muito nítida de dois pequenos episódios ocorridos na viagem de trem que fez com a família para essa ocasião (Cf. FREUD, 1987, p. 277). 
A lembrança encobridora nos ensina que uma cena esconde outra, mas sobretudo, que ela "põe em cena" significantes que engatam fantasias. Essa cena é uma "tela", portanto, que cobre a experiência traumática, mas faz ver, por meio de uma montagem complexa, elementos que permitem o desdobramento de outras cenas, as cenas da fantasia. Na lembrança que Freud analisa em "Lembranças Encobridoras", é o amarelo das flores ("deflorar") e o gosto maravilhoso do pão ("ganha-pão") que permitem que se reengatem as fantasias que o analista reconstrói em sua análise. Essas duas imagens por excelência são significantes que ancoram uma encenação mítica da própria constituição do sujeito, ao mesmo tempo velando e deixando entrever o recalcado.

Walter Benjamin, em sua "Pequena História da Fotografia", de 1931, indica uma ressonância notável entre o que faz uma fotografia e a interpretação psicanalítica. A fotografia, para ele, tem uma potência analítica, ela é capaz de revelar algo oculto à visão (o movimento de um homem que caminha, em cada fração de segundo de seu caminhar, por exemplo, na obra de Muybridge, um dos grandes precursores do cinema). "Só a fotografia", afirma Benjamin, (1994, p. 94) "revela esse inconsciente ótico, como só a psicanálise revela o inconsciente pulsional". Mas não há paralelismo entre o inconsciente "pulsional" e o "ótico": o inconsciente é "ótico" de saída, pois em seu regime trata-se sempre de "representações", como insiste Freud ao longo de toda sua obra. A pulsão nunca se revela como tal, mas se faz representar por significantes. A imagem dá testemunho, portanto, de movimentos pulsionais. Poderia então, se a pulsão não se revela, o "ótico" revelar-se, seja no cinema, seja na psicanálise? A imagem está votada, pelo menos desde o advento da fotografia, a uma análise que a conjuga à palavra. Tal analítica da imagem não se esgota, porém, em uma palavra final. A imagem está de saída ligada ao significante, como notávamos com a lembrança encobridora. A psicanálise refaz repetidamente essa ligação, produzindo novas associações para uma imagem e, logo, mais imagens para novas associações. Talvez seja nesse sentido que Freud defende tanto a idéia de que o sonho é a via régia da análise.

Toda análise, psicanalítica ou fílmica, depara-se com uma resistência da imagem, uma polissemia e uma iconicidade que põem em cheque a linguagem. A análise não é capaz de deter a imagem, mas deve se contentar em acompanhar suas errâncias ou duplicar sua fixidez. E isso não é pouco. A aproximação teórica da imagem está obrigada a vagar entre dois extremos que são, em realidade, inerentes a seu objeto: a ilusão e a impossibilidade. Tratando da fotografia em seu célebre $A$ Câmara Clara, Barthes vê nela duas vias: a que nos levaria a "submeter seu espetáculo ao código civilizado das ilusões perfeitas" e a que nos afrontaria com "o despertar da intratável realidade" (BARTHES, 1980, p. 175). O primeiro caminho é aquele que ele nomeia studium, dimensão que permite que se teçam de uma fotografia comentários sábios, sociológicos ou classificatórios. O segundo the parece mais essencial ao fotográfico: trata daquele ponto fugidio, de localização lábil, que nos obriga a fechar os olhos, diante da imagem, pois ele é pontiagudo, capaz de atingir, furar (os olhos): o punctum. Este é de localização estritamente subjetiva, justamente porque corresponde ao ponto em que a foto toca e põe em movimento pulsional o sujeito. 
A fotografia carrega já em si, portanto, uma possibilidade de movimento que o cinema virá explorar, ela cava uma distância do olhar em relação à realidade (justamente ao se propor como reprodução direta, indicial, da realidade) que faz de cada imagem uma seqüência a ser explorada, em busca de outra coisa que não está lá (exatamente como faz Freud com sua lembrança encobridora). Mas se a foto implica, em princípio, um desdobramento narrativo (studium), há nela uma corrente oposta, inerente também à imagem, que circunscreve uma certa invisibilidade, ou melhor, uma impossibilidade de ver que é correlativa a uma interrupção da sequiência narrativa, a uma parada no tempo ou a uma repetição incessante que ameaça romper toda possibilidade de narração (punctum). Há algo potencialmente traumático na imagem.

No cinema, para Barthes, essa potência destruidora da imagem fotográfica seria domesticada, no bojo da tentativa social de "temperar a loucura que ameaça constantemente explodir no rosto de quem a olha" (BARTHES, 1980, p. 172). O cinema participaria dessa pacificação social da imagem, pelo menos em sua vertente de

cinema ficcional, justamente porque é chamado de sétima arte; um filme pode ser louco por artifício, apresentar os signos culturais da loucura, jamais ele é louco por natureza (por estatuto icônico); ele é sempre o próprio contrário de uma alucinação; é simplesmente uma ilusão; sua visão é sonhadora, não ecmnésica (BARTHES, 1980, p. 172-173).

Ora, o cinema das últimas décadas parece engajado em tentar ser "louco por natureza", ao mesmo tempo em que se caracteriza como um verdadeiro construtor de "lembranças encobridoras coletivas". Por um lado, a imagem impõe-se aí com a mesma convicção perceptiva e o misterioso agenciamento com imagens ausentes que caracterizam a lembrança encobridora, e provavelmente suscita em cada expectador um movimento análogo de evocação singular de seqüências fantasmáticas. O cinema encobre, por essa vertente, o que pode haver de traumático na imagem. Por outro lado, ir ao cinema é uma experiência que apela fortemente para o corpo e o mantém imóvel, para que melhor as imagens possam colocar o sujeito em movimento (pulsional), à sua revelia (apesar de cada um perceber mais ou menos claramente o quanto se trata, ao adentrar a sala de projeção, de "assujeitar-se" a ela). Todo filme apresenta, potencialmente, um trem vindo em direção ao sujeito, como na célebre apresentação dos Lumière que assustou e fez com que se levantassem alguns expectadores. A agitação mecânica, nota incidentalmente Freud nos Três Ensaios sobre a Teoria da Sexualidade, produz excitação sexual, e é a sua conjugação com o susto que produz a neurose traumática (Cf. FREUD, 1976b, p. 190-191). Todo filme implica susto e agitação mecânica, pois obriga o sujeito a oscilar entre os sucessivos pontos de vista que a montagem cinematográfica põe em seqüência. O cinema pacifica, porém, essa violenta sujeição à imagem, ao fazê-la coletiva e massificar seus sujeitos: ali onde a literatura e as artes plásticas convocam um olhar singular, único, o cinema propõe a miragem do compartilhamento do olhar ( $\mathrm{O}$ mesmo olhar para todos! Todos em um mesmo ponto de vista, a todo momento!). 
A montagem confere ao cinema uma estrutura própria - que a sonoridade vem duplicar de forma tensa, diga-se de passagem. É por meio dessa estrutura que se pode, na produção cinematográfica atual, explorar e radicalizar a imagem em sua vertente traumática. Refaz-se, então, a lembrança encobridora, mas "ao revés" - de maneira a que a imagem pacífica dê lugar ao punctum, revelando insidiosamente o que ela deveria supostamente esconder. Pensemos na fita Irreversível, de 2002, com direção do argentino radicado na França, Gaspar Noé. Essa obra mostra, especialmente em sua primeira metade, cenas de violência bastante crua, o que de resto tornou-se quase habitual em nossos dias. Não é com isso, porém, que ela consegue a façanha de redesenhar o trauma, e sim pela sua própria estrutura narrativa em après-coup, com longas seqüências sem corte sendo agrupadas abruptamente segundo uma ordem cronológica inversa. Ela estrutura-se segundo a circularidade, a repetição, que é o funcionamento próprio da pulsão de morte (cf. FREUD, 1976a).

A inscrição que abre a fita e retorna para concluí-la circularmente é: "O Tempo Destrói Tudo". O tempo não age aí no sentido do esquecimento, do recalcamento graças ao qual a imagem encobre o passado traumático, mas, ao contrário, estrutura uma narrativa disruptiva, que ameaça todo o tempo implodir a própria possibilidade de narração. O movimento de câmera põe em cena tal circularidade, sobretudo no início do filme, em que as tomadas panorâmicas chegam a repetidas e vertiginosas rotações de 360 graus. O final do filme retoma tal vertigem em uma cena idílica da protagonista deitada num parque em um dia de verão, graças ao movimento de um aspersor que rega a grama em um jato circular, com o qual crianças brincam. A câmera o acompanha em velocidade crescente até girar sobre seu eixo, acelerando-se a ponto de fazer girar o chão e o céu, até tornar impossível qualquer imagem, forçando o sujeito a uma vertigem traumática. Não é sem ressonâncias em relação à teoria freudiana do trauma que a cena central e mais insuportável do filme, em seu realismo temporal que lhe confere cinco minutos de duração, seja a do estupro da protagonista. Mas é après-coup que ela se torna mais terrível e efetiva, ao descobrir-se, nos últimos minutos do filme, que a personagem estava grávida.

A violência não é, nessa obra, apenas mostrada em imagens: ela é posta em cena "entre" as imagens. Em seu agenciamento pulsa uma ameaçadora possibilidade de que aquilo de que se trata, que diz respeito à ligação entre sexo e violência, não possa ser contado, mas apenas repetido, o tempo destruindo tudo, circularmente. Irreversível é irresistível, porque ele nos engancha em seu tempo próprio e destrutivo. "Isso" de que se trata aí é terrível e irreversível, não há mais como fugir, pois isso "já aconteceu" (não é esse o tempo do trauma?). Faz-se necessário, então, recortar a configuração traumática e, sempre après-coup, remontá-la fantasmaticamente - numa mescla um tanto vertiginosa entre pulsões de morte e de vida, entre um filme e outro, o sujeito segue remodelando-se, interminavelmente. 


\section{REFERÊNCIAS}

BARTHES, R. A câmara clara. Rio de Janeiro: Nova Fronteira, 1980.

BENJAMIN, W. Pequena história da fotografia (1931). In: . Obras Escolhidas. Magia e técnica, arte e política. São Paulo: Brasiliense, 1994. p. 91107.

BRAUDY, J.-L. Le dispositif: approches métapsychologiques de l'impression de réalité. Communications, [S.1.], v. 23, p. 56-72, 1975.

FREUD, S. Além do princípio de prazer (1920). In: . Obras psicológicas completas. Rio de Janeiro: Imago, 1976a. v. XVIII, p. 13-85. Edição Standard Brasileira.

Lembranças encobridoras (1899). In: . Obras psicológicas completas. Rio de Janeiro: Imago, 1987. v. III, p. 269-287. Edição Standard Brasileira.

Três ensaios sobre a Teoria da Sexualidade (1905). In: . Obras psicológicas completas. Rio de Janeiro: Imago, 1976b. v. VII, p. 119-229. Edição Standard Brasileira.

; BREUER, J. Estudos sobre a histeria (1895). In: . Obras psicológicas completas. Rio de Janeiro: Imago, 1976. v. II. Edição Standard Brasileira.

IRREVERSÍVEL. Direção e produção de Gaspar Noé. França: Ressignon/NordAust Production, Grondpierre/Eskubd, 2002. DUD. cor-95 min.

Recebido em: março/2005

Aceito em: fevereiro/2006 